\title{
A Study of the Stable Boundary Layer Based on a Single-Column K-Theory Model
}

\author{
Zbigniew Sorbjan
}

Received: 11 February 2011 / Accepted: 11 August 2011 / Published online: 9 September 2011

(C) The Author(s) 2011. This article is published with open access at Springerlink.com

\begin{abstract}
We document numerical experiments with a single-column, high-resolution model of the stable boundary layer. The model resolves the logarithmic layer, and does not require inverting the Monin-Obukhov similarity functions in order to calculate the surface fluxes. The turbulence closure is based on the K-theory approach, with a new form of stability functions of the Richardson number, evaluated by using the Surface Heat Budget of the Arctic Ocean (SHEBA) and the Cooperative Atmosphere-Surface Exchange Study (CASES-99) data. A comparison with two, high-resolution large-eddy simulation models shows very good agreement. The reported numerical experiments test the effects of shear, surface cooling, the Coriolis parameter, subsidence, and baroclinicity. The time evolution of the drag coefficient, the heat-transfer coefficient, and the cross-isobar angle is also evaluated.
\end{abstract}

Keywords Baroclinicity · CASES-99 $\cdot$ K-theory model $\cdot$ Single-column model $\cdot$ SHEBA · Stable boundary layer $\cdot$ Subsidence

\section{Introduction}

An experimental effort, undertaken within recent years to study the stable boundary layer, has been motivated by the importance of nocturnal turbulence in weather prediction, climate simulations, and in environmental studies related to air pollution and wind energy applications. The consequential effort resulted in a number of programs (e.g., Cuxart et al. 2000; Kustas et al. 2004; Schwarz et al. 2004; Oncley et al. 2007; Thomas et al. 2008), and major field experiments, including the Surface Heat Budget of the Arctic Ocean (SHEBA)

\footnotetext{
Z. Sorbjan $(\varangle)$

Department of Physics, Marquette University, Milwaukee, WI 53201-1881, USA

e-mail: zbigniew.sorbjan@mu.edu

Z. Sorbjan

Institute of Geophysics, Polish Academy of Sciences, Warsaw, Poland
} 
project (e.g., Andreas et al. 1999) and the Cooperative Atmosphere-Surface Exchange Study (CASES-99) (e.g. Blumen et al. 2001; Poulos et al. 2002). Obtained observations show that instantaneous turbulent flows in stable conditions contain thin, quasi-horizontal layers with large, positive and negative vertical gradients (e.g., Sorbjan and Balsley 2008). Such layering systems are randomly distributed, a few metres deep, and many kilometres long. The stable boundary layer does not reach equilibrium (e.g., Sun et al. 2003), and is sensitive to terrain inclination, which can lead to the development of a variety of density currents and shallow drainage flows (e.g., Derbyshire and Wood 1994; Mahrt et al. 2001; Monti et al. 2002). It can be strongly affected by surface heterogeneity (e.g., Nappo 1991), radiative effects due to the presence of water vapour and water droplets (e.g., Duynkerke 1999; Ha and Mahrt 2003), meandering motions, and propagating gravity waves (e.g., Chimonas 1999; Sun et al. 2004). Stable flows are also affected by baroclinicity (Kim and Mahrt 1992), and subsidence (Mirocha and Kosovich 2010).

Stable turbulence is often assigned into one of two distinct regimes: the weakly stable state, and the very stable state (e.g., Mahrt 2003). The weakly stable regime is characterized by an overcast sky, moderate surface cooling, strong winds, and subcritical gradient Richardson numbers. The resulting potential temperature profile is of a convex shape, curved away from the Earth's surface (e.g., André and Mahrt 1982). On the other hand, the very stable regime is characterized by fair weather conditions, low winds, clear skies, and strong surface cooling. The gradient Richardson number in this case is relatively large, and the resulting turbulence very weak, leading to the development of a shallow and colder boundary layer, with concave curvature in the potential temperature profile. The very stable turbulence can have either a "continuous" or an "intermittent" character (e.g., Mahrt et al. 1998; Coulter and Doran 2002; Van de Wiel et al. 2003; Sun et al. 2004). The continuous state manifests itself with a relatively large, negative heat flux at the surface, while the intermittent turbulence is exemplified by short bursts of fluctuations, followed by events with low turbulent activity (e.g., Mahrt 2003; Mahrt and Vickers 2006).

The vertical structure of the stable turbulence can also be classified locally in terms of the Richardson number Ri (Sorbjan 2010a,b). Individual layers in the stable boundary layer can be "near neutral" when $0<R i<0.02$, "stable" for $0.02<R i<0.12$, "very stable" for $0.12<R i<0.7$, and "extremely stable", when $R i>0.7$. In the "near-neutral" regime, the gradient-based similarity functions for fluxes and variances follow the power laws, expressed in terms of the Richardson number $R i$. In the "stable" and "very stable" regimes, the similarity functions are described by empirical laws, while the generality of scaling laws in "extremely stable" conditions is doubtful.

The primary purpose of our study is to examine the evolving stable boundary layer based on a single-column model. The turbulence closure of the model uses the K-theory approach, with empirical stability functions of the Richardson number that were evaluated by using the SHEBA and CASES-99 observations (Sorbjan 2010a,b, 2011; Sorbjan and Grachev 2010). The reported numerical experiments are designed to study the effects of shear, thermal stratification, subsidence, and baroclinicity, by varying the surface cooling, the aerodynamic roughness length, the Coriolis parameter, and the geostrophic wind. The study augments similar analyses performed earlier by Delage (1974), Kim and Mahrt (1992) and Weng and Taylor (2006).

The paper has the following structure: model equations and assumptions are discussed in Sect. 2, with results presented and compared with large-eddy simulations and other singlecolumn models in Sect. 3. The effects of external parameters and external forcing are studied in Sects. 4 and 5, with final remarks provided in Sect. 6. 


\section{The Single-Column Model}

\subsection{Model Equations}

The considered single-column model (hereafter referred to as SCM) employs the ensemble-averaged, horizontally homogeneous equations of the atmospheric boundary layer in the form:

$$
\begin{aligned}
& \frac{\partial U}{\partial t}=f\left(V-V_{\mathrm{g}}\right)-\frac{\partial \tau_{x}}{\partial z}+s_{\mathrm{u}}, \\
& \frac{\partial V}{\partial t}=-f\left(U-U_{\mathrm{g}}\right)-\frac{\partial \tau_{y}}{\partial z}+s_{\mathrm{v}}, \\
& \frac{\partial \Theta}{\partial t}=-\frac{\partial H}{\partial z}+s_{\theta},
\end{aligned}
$$

where $U, V$ are the components of the wind vector, $U_{\mathrm{g}}, V_{\mathrm{g}}$, are the components of the geostrophic wind, $f$ is the Coriolis parameter, $\Theta$ is the potential temperature, $\tau_{x}, \tau_{y}, H$, are the turbulent fluxes for momentum and temperature, $z$ is height, and $t$ is time. The geostrophic wind is set to vary linearly with height: $U_{\mathrm{g}}=U_{\mathrm{go}}+T_{x} z, V_{\mathrm{g}}=V_{\mathrm{go}}+T_{y} z$, where $U_{\mathrm{go}}$ and $V_{\mathrm{go}}$ are the components of the geostrophic wind at the surface, $T_{x}=-(\beta / f) \partial \Theta / \partial y$, $T_{y}=(\beta / f) \partial \Theta / \partial x$, are the components of the thermal wind, $\beta=g / T_{\mathrm{o}}$ is the buoyancy parameter, $g$ is the acceleration due to gravity, and $T_{\mathrm{o}}$ is the reference temperature. The terms $s_{\mathrm{u}}=-w_{\mathrm{s}} \partial U / \partial z, s_{\mathrm{u}}=-w_{\mathrm{s}} \partial V / \partial z$, and $s_{\theta}=-f\left(U T_{y}-V T_{x}\right) / \beta-w_{\mathrm{s}} \partial \Theta / \partial z$ express the effects of subsidence $w_{\mathrm{S}}(<0)$, and the horizontal advection of temperature. The effects of drainage flows could also be incorporated (e.g., Sun et al. 2006), but are not included in the present version of the model. The radiative effects are taken into consideration only in the form of a constant surface-cooling rate, applied as a boundary condition.

Equations 1a and $\mathrm{b}$ are the momentum budgets, and Eq. 1c follows from the budget for the potential temperature; the humidity equation is neglected. The turbulent fluxes are evaluated based on the K-theory (Prandtl 1932):

$$
\begin{aligned}
\tau_{x} & =-K_{\mathrm{m}} \frac{\partial U}{\partial z}, \\
\tau_{y} & =-K_{\mathrm{m}} \frac{\partial V}{\partial z}, \\
H & =-K_{\mathrm{h}} \frac{\partial \Theta}{\partial z} .
\end{aligned}
$$

The eddy diffusivities, $K_{\mathrm{m}}$ and $K_{\mathrm{h}}$, are assumed to be in the form:

$$
\begin{aligned}
K_{\mathrm{m}} & =l_{\mathrm{o}}^{2} S f_{\mathrm{m}}(R i), \\
K_{\mathrm{h}} & =l_{\mathrm{o}}^{2} S f_{\mathrm{h}}(R i),
\end{aligned}
$$

where $S=\sqrt{(\partial U / \partial z)^{2}+(\partial V / \partial z)^{2}}$ is the wind shear, $R i=N^{2} / S^{2}$ is the Richardson number, $N=\sqrt{\beta \partial \Theta / \partial z}$ is the Brunt-Väisälä frequency, and $l_{\mathrm{o}}=(\sqrt{\tau} / S)_{\mathrm{o}}$ is the mixing length in neutral conditions, defined as the ratio of the momentum flux and shear at $R i=0$. Following Blackadar (1962), the mixing length can be expressed as:

$$
l_{\mathrm{o}}=\frac{\kappa z}{1+\kappa z / \lambda}
$$


where $\kappa=0.4$ is the von Karman constant, and $\lambda$ is a scaling parameter. Blackadar related the parameter $\lambda$ to two external parameters, the geostrophic wind $G$ and the Coriolis parameter $f$, viz., $\lambda=c G / f$, where $c$ is a constant, and the ratio $G / f$ can be understood as proportional to the height of the neutral boundary layer. Blackadar suggested that $c=2.7 \times 10^{-4}$. Generally, $c$ should be assumed to be dependent on the Rossby number $R o=G /\left(f z_{\mathrm{o}}\right)$, where $z_{\mathrm{o}}$ is the aerodynamic roughness length.

The empirical functions $f_{\mathrm{m}}$ and $f_{\mathrm{h}}$ are assumed to be of the form:

$$
\begin{array}{r}
f_{\mathrm{m}}(R i)=\frac{1}{\left(1+300 R i^{2}\right)^{3 / 2}}, \\
f_{\mathrm{h}}(R i)=\frac{1}{0.9\left(1+250 R i^{2}\right)^{3 / 2}},
\end{array}
$$

and which were obtained from the SHEBA observations (Sorbjan 2010a,b; Sorbjan and Grachev 2010), and verified based on the CASES-99 data (Sorbjan 2011).

\subsection{Initial and Boundary Conditions}

The above system of equations is augmented by the no-slip boundary conditions at the underlying surface, and the free-slip conditions at the top of the vertical domain, namely, at $z=z_{0}$ : $U=0, V=0, \Theta=\Theta_{\mathrm{o}}-C_{\mathrm{R}} t$, and at $z=D: \partial U / \partial z=T_{x}, \partial V / \partial z=T_{y}, \partial \Theta / \partial z=\Gamma$, where $D$ is the upper limit of the computational domain, $\Theta_{\mathrm{o}}$ is the initial surface temperature, $\Gamma$ is the gradient of the potential temperature above the boundary layer, $C_{\mathrm{R}}$ is the cooling rate, and $t$ is time.

The boundary and initial conditions follow the GEWEX Atmospheric Boundary Layer Study (GABLS) intercomparison (Beare et al. 2006, http://gabls.metoffice.com/index.html) set-up (Cuxart et al. 2006). The case chosen, studied earlier by Kosovic and Curry (2000), constitutes a moderately stable, quasi-stationary boundary layer, similar to cases commonly observed over polar regions and nighttime conditions over land in middle latitudes. The "basic set" of initial conditions describes a 100-m layer, with a constant potential temperature, $\Theta_{\mathrm{o}}=265 \mathrm{~K}$; above the 100-m deep layer, the potential temperature increases according to the gradient $\Gamma=0.01 \mathrm{~K} \mathrm{~m}^{-1}$, and a prescribed surface cooling rate of $C_{\mathrm{R}}=0.25 \mathrm{~K} \mathrm{~h}^{-1}$ is applied for $9 \mathrm{~h}$. The $x$-axis of the coordinate system is aligned with the geostrophic wind vector, with the geostrophic wind $G$ set to $8 \mathrm{~m} \mathrm{~s}^{-1}$, the Coriolis parameter $f=1.39 \times 10^{-4} \mathrm{~s}^{-1}$, which corresponds to latitude $\varphi=73^{\circ} \mathrm{N}$, and $z_{0}=0.1 \mathrm{~m}$. In the above "basic set-up", the subsidence velocity $w_{\mathrm{s}}$, and the baroclinicity parameters, $T_{x}$, and $T_{y}$, are set to zero. For $G=8 \mathrm{~m} \mathrm{~s}^{-1}, f=1.39 \times 10^{-4} \mathrm{~s}^{-1}$, and for $c=2.7 \times 10^{-4}$, suggested by Blackadar (1962), one obtains $\lambda=15.5 \mathrm{~m}$. Based on Sorbjan (2011), this value was slightly reduced, and assumed to be equal to $12 \mathrm{~m}$. For comparison, Kim and Mahrt (1992) obtained $\lambda=14.2 \mathrm{~m}$ through the use of aircraft data from three different field programs.

The "basic set-up" was slightly modified in a number of model runs, by varying selected parameters, including $z_{\mathrm{o}}$, the Coriolis parameter $f$, the surface cooling rate $C_{\mathrm{R}}$, the geostrophic wind $G$, and also by considering non-zero values of the subsidence velocity $w_{\mathrm{s}}$, and the baroclinicity parameters $T_{x}$, and $T_{y}$. Specifically, the subsidence velocity $w_{\mathrm{s}}$ was assumed zero at the surface, linearly increasing with height at $z<50 \mathrm{~m}$, and equal to $0.002 \mathrm{~m} \mathrm{~s}^{-1}$ for $z \geq 50 \mathrm{~m}$. This assumption is approximately equivalent to the case with subsidence profile S2, which was considered by Mirocha and Kosovich (2010). A slightly different profile was considered by Kim and Mahrt (1992). Because the model requires the initial shear to be non-zero, the initial boundary condition for the wind-velocity components is assumed to 
be: $U(z)=G(z / 100)^{0.5}+T_{x} z, V(z)=4(z / 100)(1-z / 100)+T_{y} z$, for $z \leq 100 \mathrm{~m}$, and $U(z)=G+T_{x} z, V(z)=T_{y} z$, for $z>100 \mathrm{~m}$. The baroclinic runs were performed for $T_{x}= \pm 1.5 \mathrm{~m} \mathrm{~s}^{-1} \mathrm{~km}^{-1}$ and $T_{y}= \pm 1.5 \mathrm{~m} \mathrm{~s}^{-1} \mathrm{~km}^{-1}$. The effects of the initial conditions were found insignificant after roughly $3 \mathrm{~h}$ of simulation.

The model equations were replaced by their finite-difference analogue, using an implicit scheme, and solved numerically by using the sweeping method in each timestep. In order to obtain sufficient accuracy, and to resolve the logarithmic sublayer, the grid spacing was very fine and non-uniform (logarithmic), with grid points located at $z_{j}=10^{\left[\zeta_{0}+(j-1) \delta z\right]}$, where $\zeta_{\mathrm{o}}=\log _{10}\left(z_{\mathrm{o}}\right), \delta z$ is the grid increment, assumed to be equal to 0.03 . The unknown values $U, V$, and $\Theta$ were defined at levels $z_{j}$, and the eddy diffusivity at midpoints $z_{j \pm 1 / 2}$. The number of grid points was typically 125 . The grid increment along the vertical coordinate changed from about $0.007 \mathrm{~m}$ near the surface to about $30 \mathrm{~m}$ near the upper boundary, and as a result the time increment had to be small, equal to $0.10-0.15 \mathrm{~s}$. Such a fine resolution enables the surface fluxes to be evaluated directly from Eqs. 3-6, without inverting the Monin-Obukhov similarity expressions, as is done in coarse resolution single-column models.

The main difference between the model introduced here and other single-column, K-theory models (e.g., Duynkerke 1991; Kim and Mahrt 1992; Galmarini et al. 1998; Beare and MacVean 2004; Edwards et al. 2006), is in the form of the applied stability functions $f_{\mathrm{m}}$ and $f_{\mathrm{h}}$, the form of the expression for the mixing length, and the value of the Prandtl number, $P r=K_{\mathrm{m}} / K_{\mathrm{h}}$.

\subsection{Diagnostic Equations}

The system (1)-(5) can be augmented by an additional set of diagnostic equations. Specifically, the standard deviations of the vertical velocity and temperature can be estimated based on the following gradient-based similarity expressions, and valid in the range $R i<0.7$ (Sorbjan 2010a,b; Sorbjan 2011):

$$
\begin{gathered}
\sigma_{\mathrm{w}}=l_{\mathrm{o}} N \frac{1}{0.85 R i^{1 / 2}\left(1+450 R i^{2}\right)^{1 / 2}}, \\
\sigma_{\theta}=l_{\mathrm{o}} \Gamma \frac{5}{\left(1+2500 R i^{2}\right)^{1 / 2}} .
\end{gathered}
$$

In the above, $N$ is the local Brunt-Väisälä frequency, and the mixing length in neutral conditions $l_{\mathrm{o}}$ is defined in (4). The product $l_{\mathrm{o}} N / R i^{1 / 2} \equiv l_{\mathrm{o}} S$ in (6a) can be regarded as the local velocity scale; similarly, the product $l_{\mathrm{o}} G$ in $(6 \mathrm{~b})$ is the local temperature scale.

The dissipation rate can be diagnosed from the steady-state turbulent energy budget in the following form (Sorbjan 2010a,b):

$$
\varepsilon=K_{\mathrm{m}} S^{2}\left(1-R_{\mathrm{f}}\right),
$$

where $R_{\mathrm{f}}=-\beta H /(\tau S)$ is the flux Richardson number, and $\tau$ is the momentum flux, $\tau=$ $\sqrt{\tau_{x}^{2}+\tau_{y}^{2}}$. Similarly, the dissipation for one-half of the temperature variance, $\varepsilon_{\theta}$, can be diagnosed from the steady-state budget in the following form (e.g., Caughey et al. 1979):

$$
\varepsilon_{\theta}=K_{\mathrm{h}} \Gamma^{2} .
$$

Noting that the flux Richardson number can be evaluated from an empirical expression, based on the gradient-based similarity (Sorbjan 2010a,b): 


$$
R_{\mathrm{f}}=\frac{R i}{0.9} \frac{\left(1+300 R i^{2}\right)^{3 / 2}}{\left(1+250 R i^{2}\right)^{3 / 2}}
$$

and that the structure parameters are defined as $C_{\mathrm{v}}^{2}=2 \varepsilon^{2 / 3}$, and $C_{\mathrm{T}}^{2}=3.2 \varepsilon_{\theta} \varepsilon^{-1 / 3}$ (e.g. Tatarski 1961), yields:

$$
\begin{aligned}
& \varepsilon=\left(l_{\mathrm{o}} N\right)^{2} N \frac{1}{R i^{3 / 2}\left(1+300 R i^{2}\right)^{3 / 2}}\left[1-\frac{R i}{0.9} \frac{\left(1+300 R i^{2}\right)^{3 / 2}}{\left(1+250 R i^{2}\right)^{3 / 2}}\right], \\
& \varepsilon_{\theta}=\left(l_{\mathrm{o}} \Gamma\right)^{2} N \frac{1}{0.9 R i^{1 / 2}\left(1+250 R i^{2}\right)^{3 / 2}}, \\
& C_{\mathrm{v}}^{2}=\frac{\left(l_{\mathrm{o}} N\right)^{2}}{l_{\mathrm{o}}^{2 / 3}} \frac{2}{R i\left(1+300 R i^{2}\right)}\left[1-\frac{R i}{0.9} \frac{\left(1+300 R i^{2}\right)^{3 / 2}}{\left(1+250 R i^{2}\right)^{3 / 2}}\right]^{2 / 3}, \\
& C_{\mathrm{T}}^{2}=\frac{\left(l_{\mathrm{o}} \Gamma\right)^{2}}{l_{\mathrm{o}}^{2 / 3}} \frac{3.56}{\left(1+250 R i^{2}\right)^{3 / 2}} \frac{\left(1+300 R i^{2}\right)^{1 / 2}}{\left[1-\frac{R i}{0.9} \frac{\left(1+300 R i^{2}\right)^{3 / 2}}{\left(1+250 R i^{2}\right)^{3 / 2}}\right]^{1 / 3}},
\end{aligned}
$$

in the range $R i<0.7$. Note that the above equations have appropriate asymptotes in neutral conditions. Specifically, when $R i=0$, then $\varepsilon=l_{\mathrm{o}}^{2} S^{3}, \varepsilon_{\theta}=0, C_{\mathrm{v}}^{2}=l_{\mathrm{o}}^{4 / 3} S^{2}$, and $C_{\mathrm{T}}^{2}=0$.

\section{Model Results}

\subsection{The "Basic Set-Up" Results}

The vertical profiles of various characteristics of turbulent flow, obtained from the 9-h basic simulation, are shown in Fig. 1. The wind-velocity components $U, V$ are depicted in Fig. 1a, and in addition to the 9-h profiles (black lines), the profiles obtained after 18-h of simulation are also shown in the figure (blue lines). The difference between the 9-h and the 18-h profiles is associated with inertial effects (e.g., Blackadar 1957; Van de Wiel et al. 2010). The effects are noticeable in the upper part of the boundary layer, from about 100 to $200 \mathrm{~m}$. They vanish above the boundary layer, as a result of the adopted initial condition, which forces the wind to become geostrophic above the boundary layer. Internal effects will be further discussed in Sect. 4.3. After nine hours of simulation, a local maximum ("low-level jet") occurs at the altitude of about $150 \mathrm{~m}$. Interestingly, after 18 hours, two local maxima can be seen in Fig. 1a, for both components of the wind velocity. Such secondary maxima, caused by inertial effects, are rarely observed in the atmosphere, due to the fact that unperturbed (by synoptic effects) nocturnal conditions usually do not last long enough.

The components of the momentum flux, $\tau_{x}$ and $\tau_{y}$, are presented in Fig. 1b. Both components decrease with height, and reach relatively small values at a level of about $170 \mathrm{~m}$, which can be identified as the boundary-layer depth. The eddy viscosity and eddy diffusivity in Fig. 1c increase with height, reach maximum values (equal to $0.75 \mathrm{~m}^{2} \mathrm{~s}^{-1}$ and $0.58 \mathrm{~m}^{2} \mathrm{~s}^{-1}$, respectively) at a level of about $25 \mathrm{~m}$, and decrease with height above. The eddy diffusivity $K_{\mathrm{h}}$ is larger than the eddy viscosity $K_{\mathrm{m}}$, which indicates that the Prandtl number $\operatorname{Pr}=K_{\mathrm{m}} / K_{\mathrm{h}}<1$ (Sorbjan and Grachev 2010).

Figure 1d depicts profiles of the Brunt-Väisälä frequency $N$ (blue line), shear $S$ (red line), and the Richardson number $R i$ (black line). Referring to the thermal stratification classification based on the values of the Richardson number (Sorbjan 2010a,b) one can verify in the 

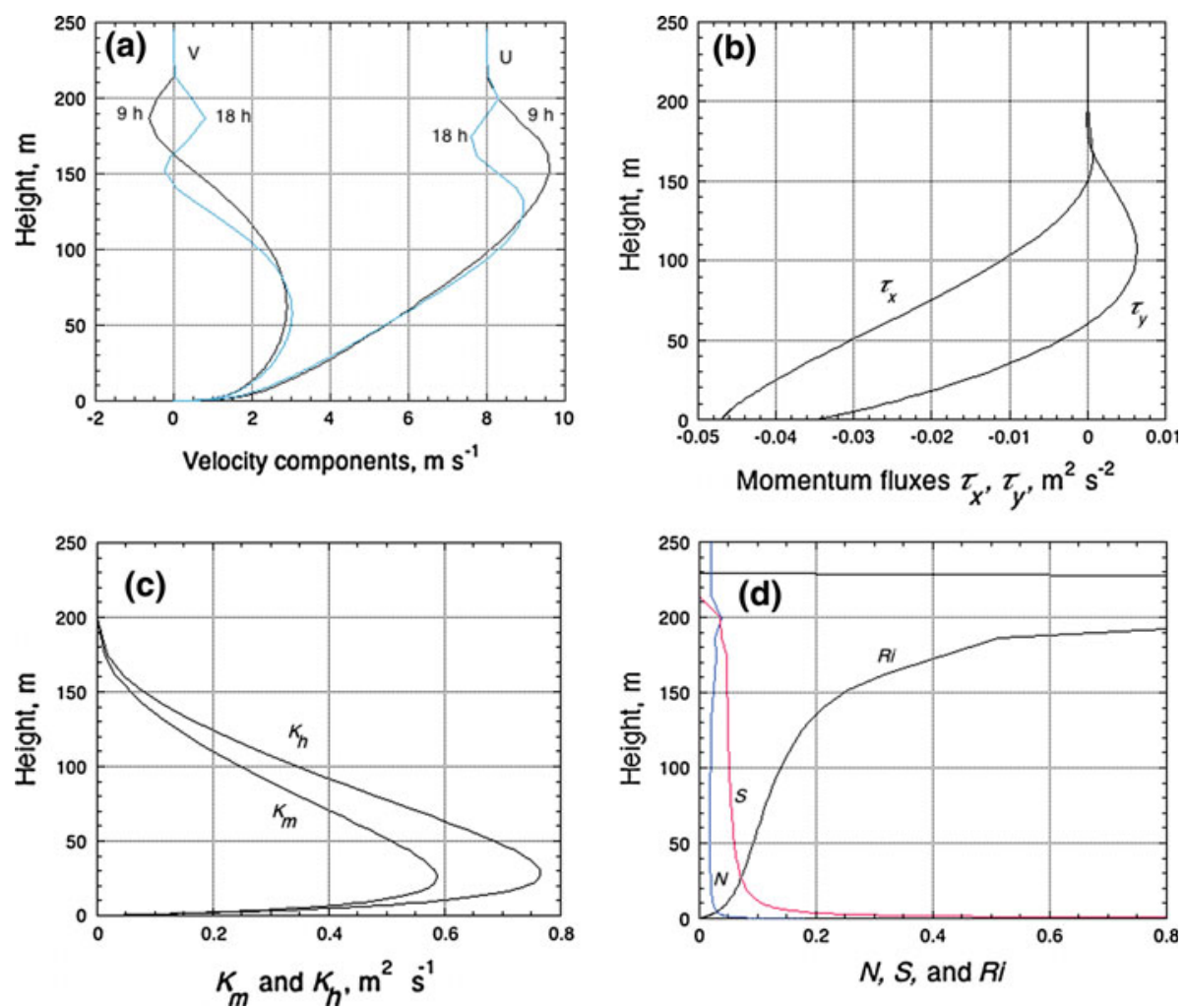

Fig. 1 Model results obtained during the 9-h basic run: a wind velocity components, $U$ and $V$ (the 18 -h profiles are marked by blue lines), b components of the momentum flux, $\tau_{x}$ and $\tau_{y}$, c coefficients $K_{\mathrm{m}}$ and $K_{\mathrm{h}}$, d the Brunt-Väisälä frequency $N$ (blue line), shear $S$ (red line), and the Richardson number Ri (black line)

figure that the "near-neutral" regime $(0<R i<0.02)$ is located within the first $3 \mathrm{~m}$ above the ground. The "stable" layer $(0.02<R i<0.12)$ extends to an altitude of about $80 \mathrm{~m}$, while the layer above, which extends up to an altitude of $190 \mathrm{~m}$, is "very stable" $(0.12<R i<0.7)$. Above the boundary layer, the Richardson number $R i$ is larger than 0.7 , which indicates that the atmosphere in this region is "extremely stable".

Based on Fig. 1 we verified that the flux-based similarity function $\psi_{\mathrm{m}}=l_{\mathrm{o}} S / U_{*}$ coincides in the boundary layer (not shown) with the similarity prediction $\psi_{\mathrm{m}}=f_{\mathrm{m}}^{-1 / 2}$, where $U_{*}=\left(\tau_{x}^{2}+\tau_{y}^{2}\right)^{1 / 4}$ is the local velocity scale, $S$ is the local shear, $l_{\mathrm{o}}$ is the mixing length described by (4), and $f_{\mathrm{m}}$ is defined by Eq. 5a. Similarly, the flux-based similarity function for the potential temperature, $\psi_{\mathrm{h}}=l_{\mathrm{o}} \Gamma / \vartheta_{*}$, coincides (not shown) with the similarity prediction $\psi_{\mathrm{h}}=f_{\mathrm{m}}^{1 / 2} / f_{\mathrm{h}}$, where $\vartheta_{*}=-H / U_{*}$ is the local temperature scale, $\Gamma$ is the potential temperature gradient, and $f_{\mathrm{m}}, f_{\mathrm{h}}$ are given by Eqs. 5a, b. As pointed out by Sorbjan (2011), this result can be understood as an extension of the Monin-Obukhov similarity formulation above the stable surface layer.

Diagnosed values of the dissipation rates, $\varepsilon, \varepsilon_{\theta}$ (not shown), decrease with height and reach very small values at the top of the boundary layer, with both structure parameters, $C_{\mathrm{v}}^{2}$, $C_{\mathrm{T}}^{2}$, also decreasing with height. Above the top of the boundary layer, $C_{\mathrm{T}}^{2}$ is undefined, where the dissipation rate $\varepsilon$ falls to zero. 

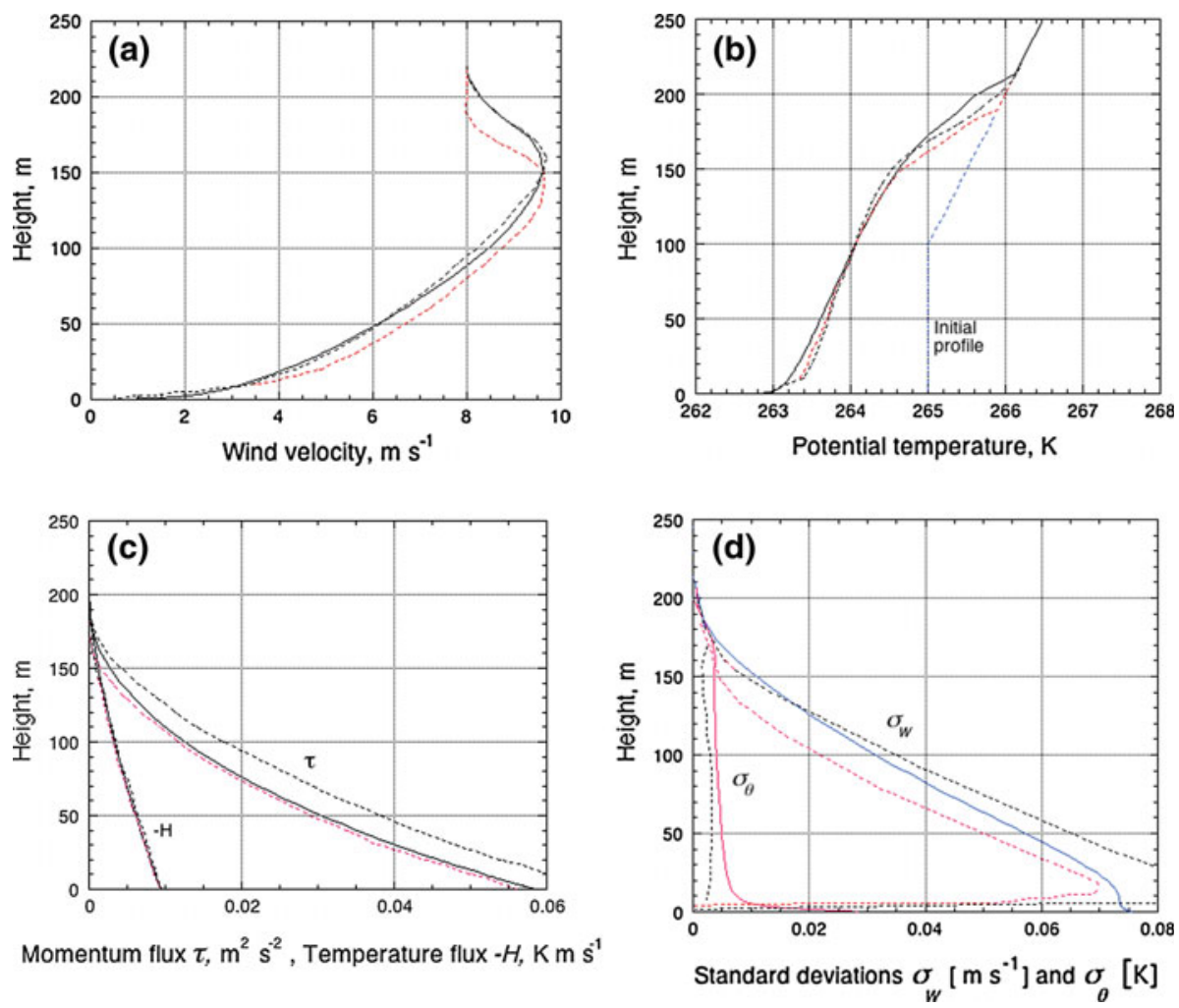

Fig. 2 A comparison of the single-column model results (solid lines) with two large-eddy simulations (dashed lines): a wind velocity modulus, b potential temperature (the initial profile is marked by a blue dashed line), c momentum $\tau$ and temperature $H$ fluxes, $\mathbf{d}$ standard deviations, $\sigma_{\mathrm{W}}$ and $\sigma_{\theta}$, for the vertical velocity and temperature. The Met Office LES model is marked by black dashed lines, the University of Hannover LES model is indicated by red dashed lines

\subsection{Comparison with Large-Eddy Simulations and Other Single-Column Models}

Figure 2 shows a comparison of the SCM results with the results of two, high-resolution, large-eddy simulation (LES) models. The first model was developed in the UK Met Office (Brown et al. 1994; Beare and MacVean 2004), and the second at the University of Hannover (Raash and Etling 1991; Raash and Schröter 2001). Both simulations were performed for the same initial and boundary conditions, prescribed as part of the GABLS intercomparison.

The agreement of the SCM and LES in Fig. 2 is very good, where the SCM results are presented as solid lines in the figure, and the LES results are indicated by dashed lines. The Met Office LES model (BMO) is marked by black dashed lines, and the University of Hannover LES model (UH) is indicated by red dashed lines. The wind velocity (modulus) in Fig. 2a nearly coincides with the BMO profile. In the UH model, the maximum velocity is reached at $z=140 \mathrm{~m}$, slightly below the level of the low-level jet indicated by the SCM, and produces lower values of wind speed above $z=150 \mathrm{~m}$.

The potential temperature profiles are shown in Fig. 2b. All three models show that the surface temperature decreases to $263 \mathrm{~K}$, which is enforced by the surface boundary condition, and all resulting temperature profiles have convex curvatures above the surface layer. In that 
layer from about 150 to $210 \mathrm{~m}$, the SCM temperature is $0.1-0.5 \mathrm{~K}$ lower than that obtained from both LES models.

The momentum flux $\tau=\sqrt{\tau_{x}^{2}+\tau_{y}^{2}}$, and the negative heat flux $-H$, are depicted in Fig. 2c, where the SCM fluxes coincide with the UH profiles. The BMO model produces larger values of the momentum flux, and the agreement of the heat flux profiles is excellent. There is also good agreement of the standard deviations for the vertical velocity $\sigma_{\mathrm{w}}$ and temperature $\sigma_{\theta}$ in Fig. 2d. The standard deviations for temperature, $\sigma_{\theta}$, produced by SCM, strongly decreases with height in the surface layer, and is nearly constant above it. The standard deviations for the vertical velocity, $\sigma_{\mathrm{w}}$, monotonically decreases with height. Note that the LES profiles show only the resolvable part of $\sigma_{\mathrm{w}}$ and $\sigma_{\theta}$.

A comparison of the SCM with the single-column models participating in the GABLS single-column model intercomparison (Cuxart et al. 2006, http://turbulencia.uib.es/gabls) exhibits larger discrepancies (not shown). The main differences between the SCM presented here, and other single-column models (research and operational ones), are in the form of the stability functions $f_{\mathrm{m}}$ and $f_{\mathrm{h}}$, and in the form of the value of the adjustable parameter $\lambda$. The values of $\lambda$, for the single-column models during the GABLS intercomparison varied between 40 and $200 \mathrm{~m}$, which is significantly larger that the value of $12 \mathrm{~m}$ adopted here.

Generally, operational models utilize the "pragmatic" form of stability functions, which slowly decay with $R i$, and cause higher mixing efficiencies, than would be expected based on local observations. As a consequence, such models avoid "decoupling" caused by an excessive cooling near the surface over land points, which improves operational verification scores. Nevertheless, they fail to produce the local development of the upper inversion, and overestimate the local surface friction velocity (Cuxart et al. 2006; Beare et al. 2006). The "long-tail" form of the stability functions can be understood as an attempt to parametrize the effects of subgrid-scale inhomogeneities within weather prediction and general circulation models, and to take into consideration local drainage flows over hilly areas. Validation against local measurements, however, seems to show that the approach causes mixing that is too strong in areas with little subgrid-scale topographic variations (e.g., Sarijarvi 2009).

The differences among various models can be expressed in terms of several characteristics, such as the boundary-layer height $h$ (e.g., defined as the height at which the stress falls to $5 \%$ of its surface value, divided by 0.95 ), the surface temperature flux $H_{0}$, the friction velocity $u_{*}$, the Obukhov length $L_{*}$, and the cross-isobar angle $\alpha$. The average values of these parameters for research models during the GABLS intercomparison were: $h=$ $208 \mathrm{~m}, H_{\mathrm{o}}=-0.013 \mathrm{Km} \mathrm{s}^{-1}, u_{*}=0.29 \mathrm{~m} \mathrm{~s}^{-1}, L_{*}=130 \mathrm{~m}, \alpha=36^{\circ}$ (Cuxart et al. 2006). The SCM results presented here are lower for most of the considered parameters: $h=158 \mathrm{~m}, H_{\mathrm{o}}=-0.009 \mathrm{Km} \mathrm{s}^{-1}, u_{*}=0.24 \mathrm{~m} \mathrm{~s}^{-1}, L_{*}=100 \mathrm{~m}, \alpha=37^{\circ}$. In a similar study, Weng and Taylor (2006) obtained, through the use of a 1.5-order turbulence closure scheme, that $h=175 \mathrm{~m}, H_{\mathrm{o}}=-0.011 \mathrm{Km} \mathrm{s}^{-1}, u_{*}=0.27 \mathrm{~m} \mathrm{~s}^{-1}, L_{*}=122 \mathrm{~m}$, $\alpha=36^{\circ}$.

\section{Effects of External Parameters}

In this section we briefly review numerical experiments with the SCM, performed to test the effects of external parameters on the structure of the stable boundary layer. 

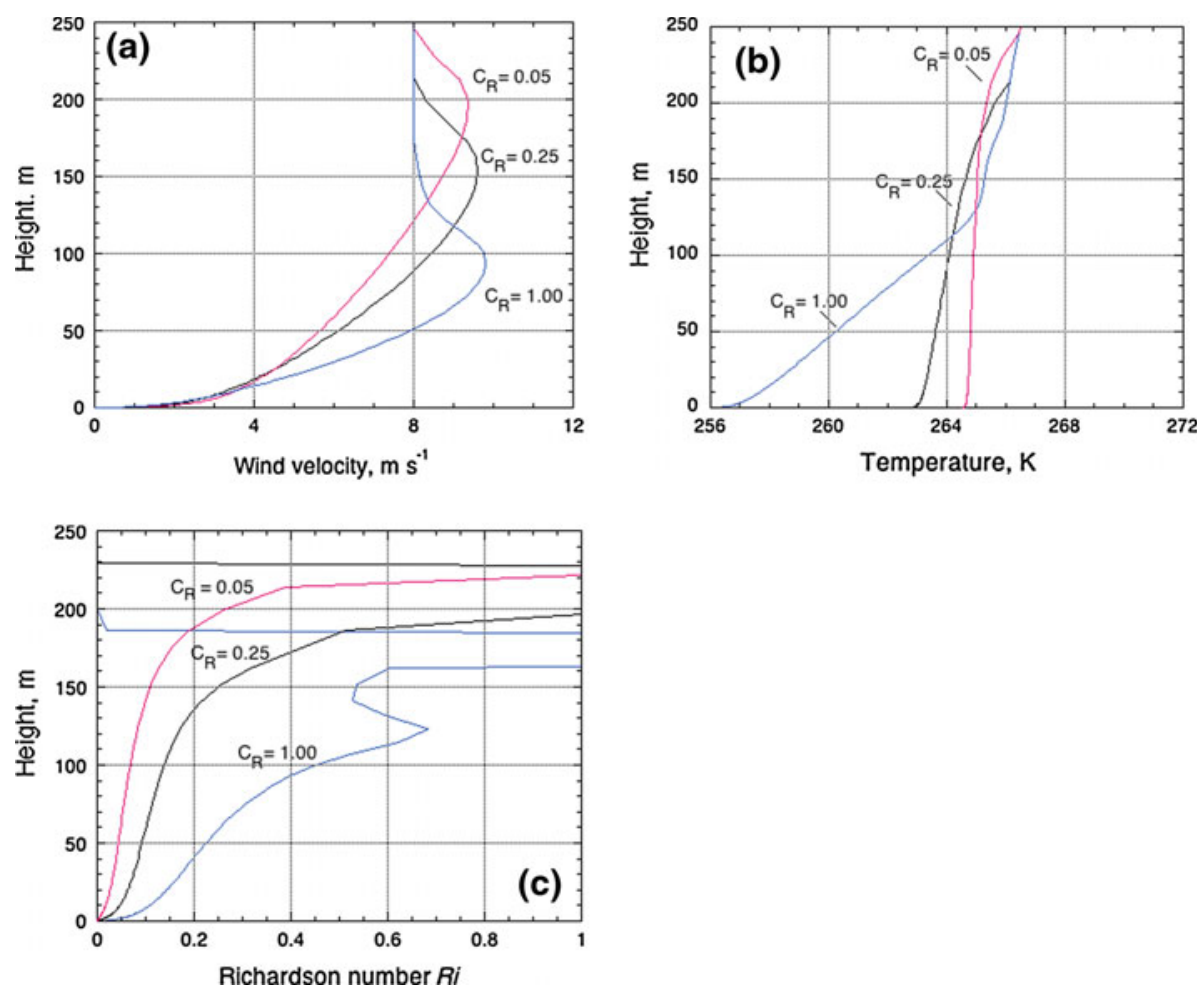

Fig. 3 Effects of the surface cooling rate $C_{\mathrm{R}}$ : a wind velocity modulus, b potential temperature, $\mathbf{c}$ Richardson number Ri. Profiles obtained in the 9-h run, for $C_{\mathrm{R}}=1.0 \mathrm{~K} \mathrm{~h}^{-1}$ (blue line), $C_{\mathrm{R}}=0.25 \mathrm{Kh}^{-1}$ (black lines), $C_{\mathrm{R}}=0.05 \mathrm{Kh}^{-1}$ (red lines)

\subsection{Surface Cooling}

Effects of surface cooling on the structure of the stable boundary layer are depicted in Fig. 3, where profiles were obtained for three cooling rates, $C_{\mathrm{R}}=1.0 \mathrm{~K} \mathrm{~h}^{-1}$ (blue lines), $0.25 \mathrm{~K} \mathrm{~h}^{-1}$ (black lines), and $0.05 \mathrm{~K} \mathrm{~h}^{-1}$ (red lines). For $C_{\mathrm{R}}=0.05 \mathrm{Kh}^{-1}$, the potential temperature, in Fig. 3b, is nearly constant with height, and with increasing values of $C_{\mathrm{R}}$, the boundary layer becomes more stable. When the cooling rate increases, the level $h_{\mathrm{m}}$ of the maximum velocity decreases (Fig. 3a), and values of the Richardson number within the boundary layer increases (Fig. 3c).

The height of the boundary layer $h_{\mathrm{f}}$ can be defined as the level at which the stress falls below $1 \%$ of its surface value. For $C_{\mathrm{R}}=0.05 \mathrm{~K} \mathrm{~h}^{-1}, h_{\mathrm{f}} \approx 230 \mathrm{~m}$ and $h_{\mathrm{m}} \approx 200 \mathrm{~m}$, and for $C_{\mathrm{R}}=1.0 \mathrm{Kh}^{-1}, h_{\mathrm{f}} \approx 105 \mathrm{~m}$ and $h_{\mathrm{m}} \approx 90 \mathrm{~m}$. The corresponding values of the Obukhov length are: $L_{*}=1,480 \mathrm{~m}$ for $C_{\mathrm{R}}=0.05 \mathrm{Kh}^{-1}$, and $L_{*}=12 \mathrm{~m}$ for $C_{\mathrm{R}}=1.0 \mathrm{Kh}^{-1}$, which yields the values of the ratio $h_{\mathrm{f}} / L_{*}$ equal to 0.16 for $C_{\mathrm{R}}=0.05 \mathrm{Kh}^{-1}$, and $h_{\mathrm{f}} / L_{*}=8.75$ for $C_{\mathrm{R}}=1.0 \mathrm{~K} \mathrm{~h}^{-1}$. The Richardson number profiles, in Fig. $3 \mathrm{c}$, allow identifying the thermal stratification depending on the cooling rate. For $C_{\mathrm{R}}=0.05 \mathrm{Kh}^{-1}$, the boundary layer can be classified as "stable" $(0.02<R i<0.12)$ up to $z \approx 170 \mathrm{~m}$, and as "very stable" $(0.12<R i<0.7)$ in the layer from 170 to about $220 \mathrm{~m}$. For $C_{\mathrm{R}}=1.0 \mathrm{Kh}^{-1}$, the boundary layer is "stable" up to $z \approx 15 \mathrm{~m}$, and "very stable" in the layer from $15 \mathrm{~m}$ to the top of the boundary layer at $z \approx 120 \mathrm{~m}$. 

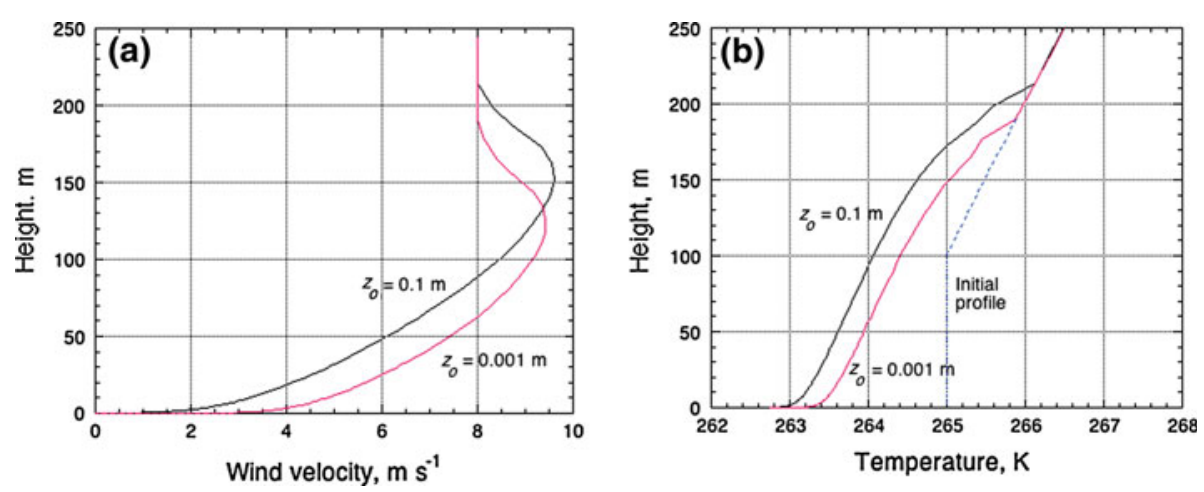

Fig. 4 Effects of the roughness length $z_{0}$ : a wind velocity modulus, b potential temperature. Profiles obtained in the 9 -h basic run with $z_{0}=0.1 \mathrm{~m}$ are marked by black lines. Profiles obtained for $z_{0}=0.001 \mathrm{~m}$ are indicated by red lines

\subsection{Surface Roughness}

Figure 4 shows vertical profiles of wind velocity, potential temperature, obtained for two values of the roughness parameter, $z_{0}=0.1 \mathrm{~m}$ and for $z_{0}=0.001 \mathrm{~m}$. Profiles obtained for $z_{\mathrm{o}}=0.1 \mathrm{~m}$ are marked by black lines, while profiles obtained for $z_{\mathrm{o}}=0.001 \mathrm{~m}$ are indicated by red lines. As shown in Fig. 4a, when the roughness parameter is small, the wind speed near the surface is greater, decreasing the shear $S$ in the boundary layer, and reducing the turbulence production. The smaller $z_{\mathrm{o}}$ becomes, the shallower is the boundary layer; for $z_{\mathrm{o}}=0.001 \mathrm{~m}$, $h_{\mathrm{f}} \approx 140 \mathrm{~m}$ and $h_{\mathrm{m}} \approx 120 \mathrm{~m}$, while for $z_{\mathrm{o}}=0.1 \mathrm{~m}, h_{\mathrm{f}} \approx 170 \mathrm{~m}$ and $h_{\mathrm{m}} \approx 150 \mathrm{~m}$. Similarly, the smaller is the roughness length $z_{\mathrm{o}}$, the smaller are the turbulent fluxes (not shown), and the less effective is diffusion from the vicinity of the cold surface upward. As a result, the potential temperature within the boundary layer is larger for $z_{0}=0.001 \mathrm{~m}$, than is the case for $z_{\mathrm{o}}=0.1 \mathrm{~m}$ (Fig. 4b).

\subsection{Coriolis Parameter}

Inertial effects related to the Coriolis parameter are illustrated in Fig. 5. The wind speed and potential temperature profiles in Fig. 5a and $\mathrm{b}$, obtained for $f=1.39 \times 10^{-4} \mathrm{~s}^{-1}$, are marked by black lines, while the results for $f=0.8 \times 10^{-4} \mathrm{~s}^{-1}$ are indicated by red lines. The difference between the black and red profiles is caused by different values of the inertial period $T_{i}(\mathrm{hrs})=2 \pi / f=12 / \sin (\varphi)$, in which the angle between the ageostrophic wind vector and the $x$-axis changes by $2 \pi$. The inertial period $T_{i}$ is equal to $12 \mathrm{~h}$ at the North and South Poles, and is infinite at the equator. For $f=0.8 \times 10^{-4} \mathrm{~s}^{-1}$ (latitude $\varphi=33.4^{\circ}$, red profiles), $T_{i}$ is equal to $21.8 \mathrm{~h}$, and for $f=1.39 \times 10^{-4} \mathrm{~s}^{-1}$ (latitude $\phi=73^{\circ}$, black profiles) $T_{i}=12.6 \mathrm{~h}$. Consequently, the boundary layer at the latitude of $33.4^{\circ}$ evolves more slowly. This implies that the red profiles attain the exact form of the black profiles after $15.57 \mathrm{~h}$ of simulation (i.e., after additional $6.57 \mathrm{~h}$ ), but only in neutral conditions. They would be slightly different (with respect to black profiles) in stable conditions, because the potential temperature after $15.57 \mathrm{~h}$ of surface cooling would be different (lower) than its value after $9 \mathrm{~h}$ of cooling.

Figure 5c shows three hodographs of the wind-velocity components at three fixed levels, $z=11.7,93.3$, and $185.2 \mathrm{~m}$, obtained in the 18 -h basic run for $f=1.39 \times 10^{-4} \mathrm{~s}^{-1}$. The 

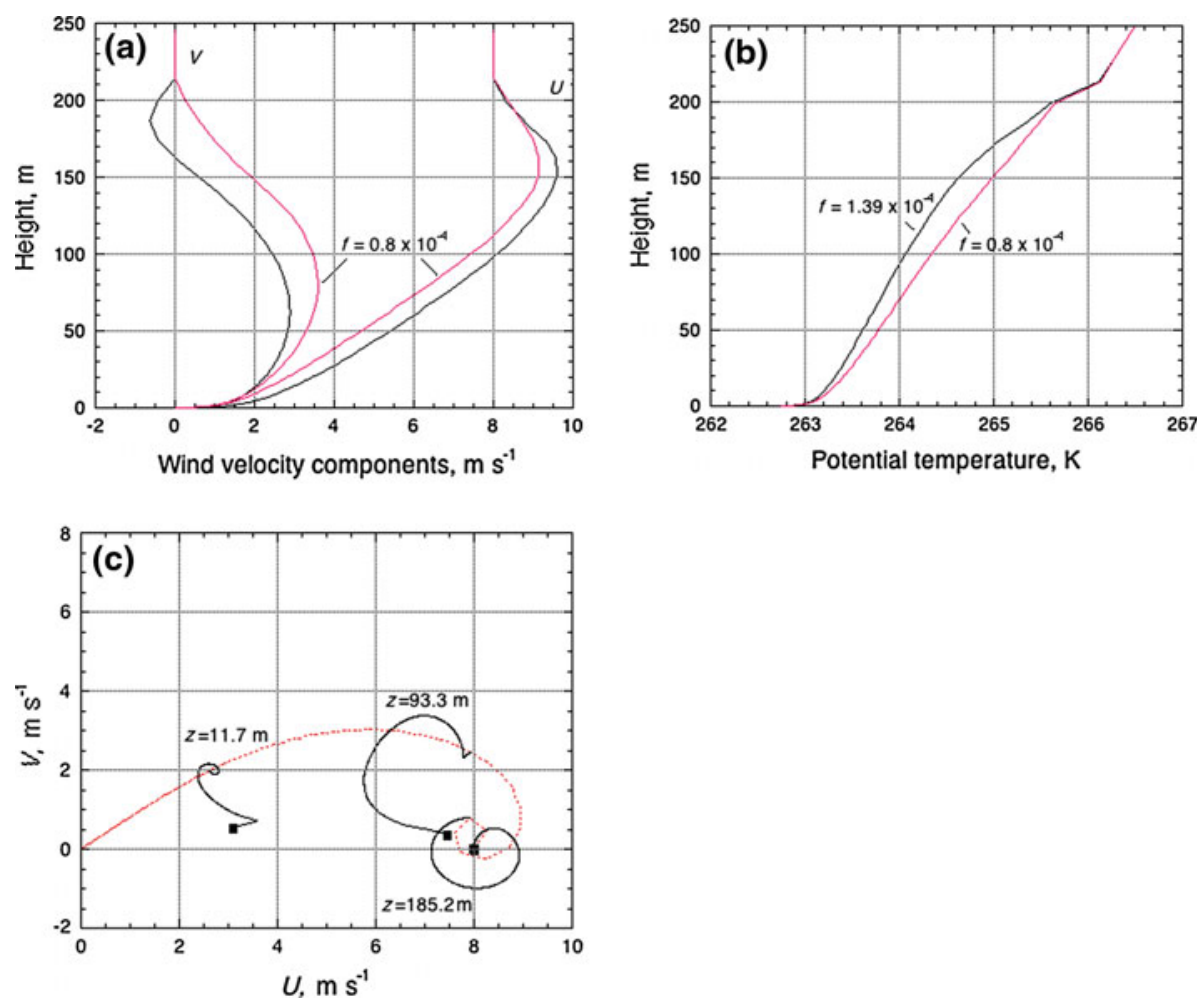

Fig. 5 Inertial effects: a wind velocity components, and b potential temperature profiles obtained in the 9-h basic run for $f=1.39 \times 10^{-4} \mathrm{~s}^{-1}$ (black lines), and for $f=0.8 \times 10^{-4} \mathrm{~s}^{-1}$ (red lines), c hodographs of wind velocity components at three fixed levels, $z=11.7,93.3$, and $185.2 \mathrm{~m}$, obtained in the 18-h basic run $\left(f=1.39 \times 10^{-4} \mathrm{~s}^{-1}\right)$. The initial points of each hodograph are marked by black squares. The Ekman-type spiral, at the end of the 18-h run, is marked by the red dotted line

Ekman-type spiral, plotted at the end of the 18-h basic run, is also depicted, and marked by the red dotted line. The initial point of each fixed-level hodograph is identified by a black square, while the final points are located at the Ekman-type spiral. At a given height $z$, circulation along each fixed-level hodograph is clockwise, since the simulation is performed for the Northern Hemisphere.

\subsection{Shear}

The effects of a weak shear are simulated by assuming the geostrophic wind $G=2 \mathrm{~m} \mathrm{~s}^{-1}$, and the results are displayed in Fig. 6. The height of the boundary layer in this case is approximately $h_{\mathrm{f}}=60 \mathrm{~m}$, with the resulting surface-layer scales $u_{*}=0.049 \mathrm{~m} \mathrm{~s}^{-1}, T_{*}=0.031 \mathrm{~K}$, $L_{*}=5.36 \mathrm{~m}$. Figure 6 a shows the wind-velocity modulus $W$, with the profile being logarithmic (the dotted blue line) up to about $0.5 \mathrm{~m}$. Above this level, the wind velocity follows the log-linear curve of Businger et al. (1971), up to the level of about $10 \mathrm{~m}$ (red solid line). The low-level jet occurs at about $35 \mathrm{~m}$ above the surface, and at the level of $z \approx 65 \mathrm{~m}$, the wind velocity modulus has a local minimum.

Figure $6 \mathrm{~b}$ shows the potential temperature. The temperature profile has a concave curvature and is logarithmic, up to the level of about $1 \mathrm{~m}$ (the dotted blue line), and above this 

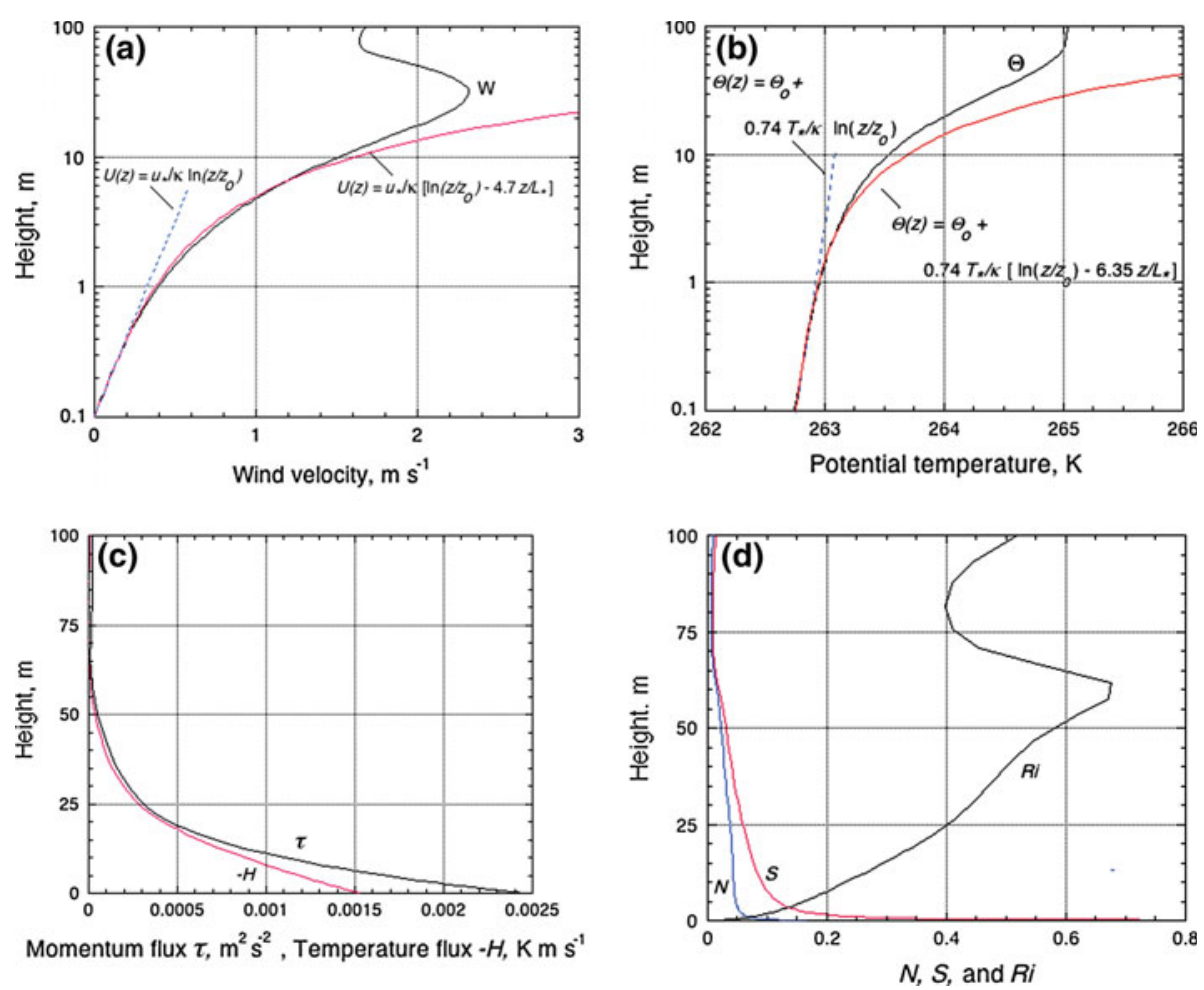

Momentum flux $\tau, \mathrm{m}^{2} \mathrm{~s}^{-2}$, Temperature flux $-\mathrm{H}, \mathrm{K} \mathrm{m} \mathrm{s}$

Fig. 6 Effects of a weak shear, obtained in the 9-h run for $G=2 \mathrm{~ms}^{-1}$. Profiles of: a the wind modulus $W$, and $\mathbf{b}$ potential temperature $\Theta, \mathbf{c}$ momentum $\tau$ and temperature $H$ fluxes, $\mathbf{d}$ the Brunt-Väisälä frequency $N$, shear $S$, and the Richardson number Ri. The logarithmic profiles in $\mathbf{a}$ and $\mathbf{b}$ are marked by the blue lines, the surface-layer similarity profiles of Businger et al. (1971) are marked by red lines

level, the potential temperature follows the log-linear curve of Businger et al. (1971), up to the level of about $5 \mathrm{~m}$ (red solid line). The momentum and heat fluxes, $\tau$ and $-H$, are shown in Fig. 6c, with the fluxes monotonically decreasing with height, and are non-linear. The Richardson number in Fig. 6d indicates that almost the entire boundary layer (except for a very thin layer near the surface) is "very stable" $(0.12<R i<0.7)$. The level at which, the Richardson number reaches a maximum coincides with the height of the boundary layer. The most intense turbulence occurs near the surface.

According to Mahrt (1999), the stable regime may assume an "upside-down" structure, with the strongest turbulence at the top of the surface-inversion layer, where it is generated by vertical shear on the underside of the lower-level jet. Near the ground, the flow can be nearly laminar, and detached from the rest of the boundary layer. A similar phenomenon was earlier described by Businger (1973), as taking place on clear nights, when thermal stratification increases due to the strong cooling of the surface. The "upside down" turbulence is considered a transient phenomenon, although this has not been formally documented very well in the literature.

As follows from Figs. 1 and 6, the described "upside-down" boundary layer cannot be achieved within the presented simulations. When the cooling rate at the surface is increased, the thermal stratification increases, and the depth of the boundary layer decreases. As a consequence, the wind shear $S$ increases, causing the Richardson number near the surface to 
be come subcritical. Decreasing the wind speed does not change this situation, as the strongest turbulence always appears near the surface where shear is the greatest. The inability of the SCM to simulate the "upside-down" case could be associated with the fact that the single-column model does not support the effects of breaking gravity waves.

\subsection{Internal Versus External Scales and Parameters}

System (1)-(6) is governed by five external parameters: the geostrophic wind $G$, the roughness length $z_{\mathrm{o}}$, the cooling rate $C_{\mathrm{R}}$, the Coriolis parameter $f$, and the buoyancy parameter $\beta$. Based on these parameters, three external scales can be formed: $G$ for velocity, $T_{\mathrm{S}}=C_{\mathrm{R}} / f$ for temperature, and $f^{-1}$ for time. The order of magnitude for these scales is: $[G] \approx 10 \mathrm{~m} \mathrm{~s}^{-1}$, $\left[T_{\mathrm{s}}\right] \approx 1 \mathrm{~K},\left[f^{-1}\right] \approx 3 \mathrm{~h}$. There are two external height scales of the system: $z_{\mathrm{o}}$ and the ratio $G / f$. Both are significantly different from the depth of the stable boundary layer, $\left[z_{\mathrm{o}}\right] \approx 10^{-3}-10^{-1} \mathrm{~m},[G / f] \approx 10^{5} \mathrm{~m}$. From the external parameters, two dimensionless parameters can be formed, the Rossby number $R o=G /\left(f z_{\mathrm{o}}\right)$, and the external stability parameter $\mu=\beta C_{\mathrm{R}} /\left(f^{2} G\right)$. A similar, external stability parameter was defined by Delage (1974). The typical order of magnitude for these numbers is: $[R o] \approx 10^{5}-10^{7}$, and for $[\mu] \approx 10^{1}-10^{2}$. As vital internal parameters, one can consider the surface-layer scales $u_{*}$, $T_{*}$, and $L_{*}$, together with the cross-isobar angle $\alpha$ between the geostrophic wind and the surface wind.

The dimensional analysis indicates that the ratios of the internal and external parameters, and also values of the cross-isobar angle $\alpha$, are functions of the Rossby number $R o$, the stability parameter $\mu$, and the dimensionless time $t f$ :

$$
\begin{aligned}
\frac{u_{*}}{G} & =f_{\mathrm{u}}(R o, \mu, t f), \\
\frac{T_{*}}{T_{\mathrm{s}}} & =f_{\mathrm{T}}(R o, \mu, t f), \\
\alpha & =f_{a}(R o, \mu, t f) .
\end{aligned}
$$

An approach based on similar principles and referred to as the Rossby-number similarity theory was developed in the 1960s and 1970s, with an additional assumption of quasi-stationarity.

Figure 7 shows the time history of the drag coefficient $u_{*} / G$, the cross-isobar angle $\alpha$, and the heat-transfer coefficient $T_{*} / T_{\mathrm{S}}$, for given values of the Rossby number $R o$ and the stability parameter $\mu$, based on four runs with $z_{\mathrm{o}}=0.001 \mathrm{~m}, z_{\mathrm{o}}=0.1 \mathrm{~m}, C_{\mathrm{R}}=0.05 \mathrm{Kh}^{-1}$, $C_{\mathrm{R}}=0.25 \mathrm{Kh}^{-1}$, and for $f=1.39 \times 10^{-4}\left(T_{i}=12.5 \mathrm{~h}\right)$. Note that the dimensionless time If is indicated at the upper edge of each plot. The figure indicates that the drag coefficient $u_{*} / G$ decreases when $R o$ increases, and decreases when $\mu$ increases. The cross-isobar angle $\alpha$ decreases when Ro increases, and increases when $\mu$ increases. On the other hand, the heattransfer coefficient $T_{*} / T_{\mathrm{S}}$ decreases when $R o$ increases, and decreases when $\mu$ increases. The above rules apply for all time. The drag coefficient $u_{*} / G$ and the cross-isobar angle $\alpha$ exhibit inertial oscillations with the period of $T_{i}$; the heat-transfer coefficient $T_{*} / T_{\mathrm{s}}$, however, monotonically increases with time.

For large values of time, the ratio $T_{*} / T_{\mathrm{s}}$ flattens, and the temperature flux $H$ becomes a linear function of height, $H=H_{\mathrm{o}}\left(1-z / h_{\mathrm{c}}\right)$, where $H_{\mathrm{o}}$ is the surface heat flux, and $h_{\mathrm{c}}$ can be referred to as the equilibrium height of the steady-state stable boundary layer. Since $d H / d z$ is constant with height, and equal to $-H_{\mathrm{o}} / h_{\mathrm{c}}$, the cooling rate $\partial \Theta / \partial t$ (Eq. 1c) must also be constant, and equal to the surface cooling rate $C_{\mathrm{R}}$. This allows evaluating $h_{\mathrm{c}}$ as: 

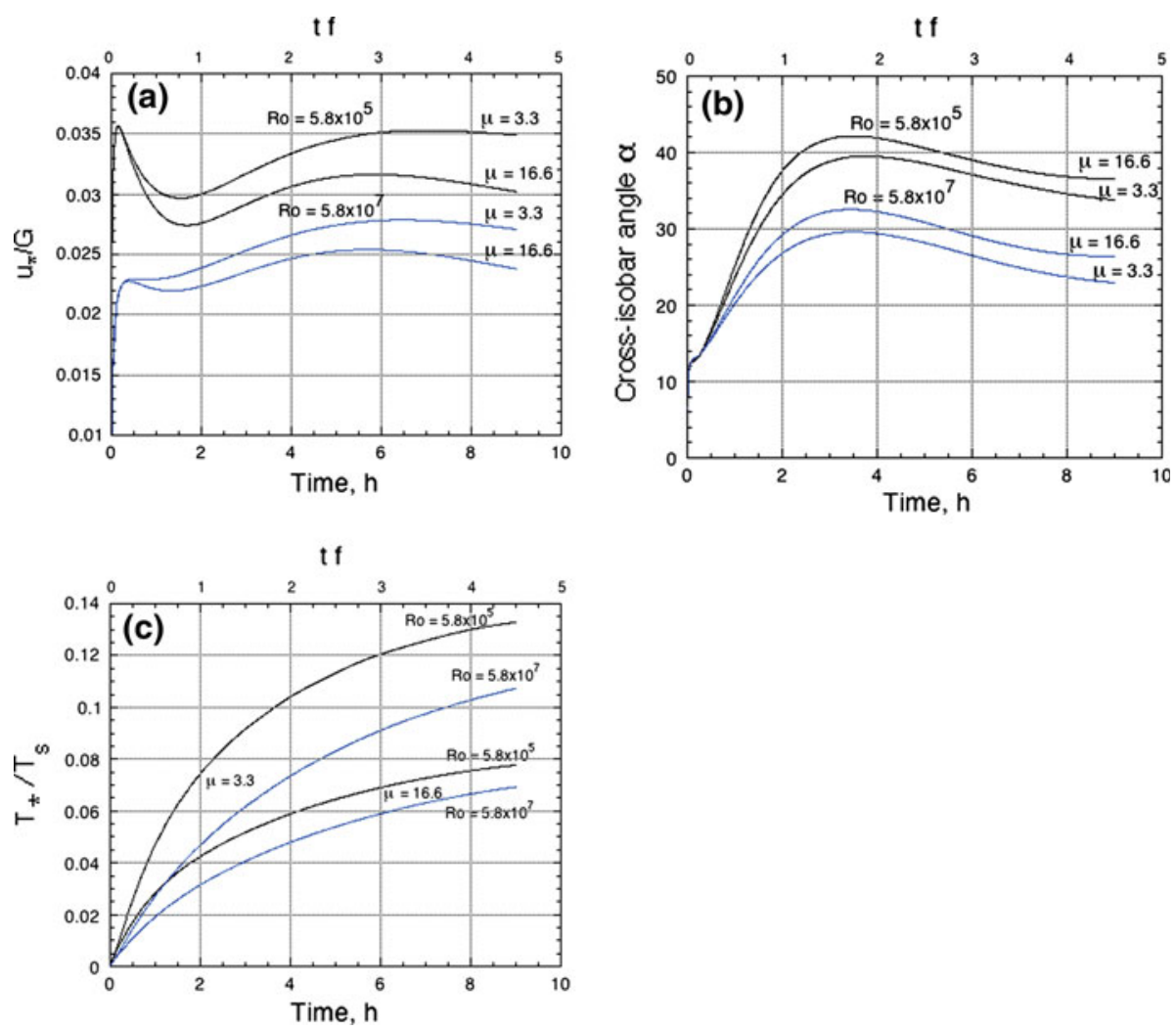

Fig. 7 Time history of: a the drag coefficient $u_{*} / G, \mathbf{b}$ the cross-isobar angle $\alpha$, $\mathbf{c}$ the heat-transfer coefficient $T_{*} / T_{\mathrm{S}}$, for given values of the Rossby number $R o$ and the stability parameter $\mu$. The dimensionless time $t f$ is indicated on the upper edge of the plot

$$
h_{\mathrm{c}}=-\frac{H_{\mathrm{O}}}{C_{\mathrm{R}}} .
$$

One of the characteristic features of the stable boundary layer is that scales of height are not unique. For example, the following scales for height can be considered: the Ekman scale $L_{\mathrm{E}}=u_{*} / f$, the Obukhov scale $L_{*}$, and the scale $L_{Z}=\left(L_{*} L_{\mathrm{E}}\right)^{1 / 2}$ (Zilitinkevich 1972). The scales can be used to estimate the depth of the stable boundary layer. Figure 8 shows the time series of such estimates, obtained by using the 9 -h basic run. In the figure, $h_{\mathrm{c}}$ is obtained from (13), while $h_{Z}=0.4 L_{Z}$ (e.g., Garratt 1982), and $h_{\mathrm{E}}=0.1 L_{\mathrm{E}}$. Moreover, $h_{\mathrm{m}}$ is the height of the maximum wind velocity, and $h_{\mathrm{f}}$ is the height at which the stress falls below $1 \%$ of its surface value. The lines in Fig. 8, which represent $h_{\mathrm{m}}$ and $h_{\mathrm{f}}$, were evaluated at the nearest grid point of the SCM, and since the resolution of SCM near the top of the boundary is coarse, the value of $h_{\mathrm{f}}$ at the end of the run is larger than the value that can be obtained from Fig. 1b.

As follows from Fig. 8, values of $h_{\mathrm{f}}$ increase with time during the first four hours of the simulation, and remain equal to $200 \mathrm{~m}$ later on. Values of $h_{\mathrm{m}}$ reach a maximum at the third hour of the simulation, and then decrease to $150 \mathrm{~m}$. The remaining estimates of the boundary-layer depth vary during the simulation, and at the end of the simulation, $h_{\mathrm{E}}$ and $h_{Z}$ coincide, and are approximately equal to the value of $h_{\mathrm{f}}$, obtained from Fig. $1 \mathrm{~b}$. 
Fig. 8 Scales of height during the 8-h simulation of the basic run: $h_{\mathrm{f}}$-the height at which the stress falls below $1 \%$ of its surface value, $h_{\mathrm{w}}$ - the height where the wind velocity is maximum, $h_{\mathrm{c}}=H_{\mathrm{O}} / C_{\mathrm{R}}$, $h_{z}=0.4\left(L_{\mathrm{E}} L_{*}\right)^{1 / 2}$ (where $\left.L_{\mathrm{E}}=u_{*} / f\right), h_{\mathrm{E}}=0.1 L_{\mathrm{E}}$, and $L_{*}$ is the Obukhov scale
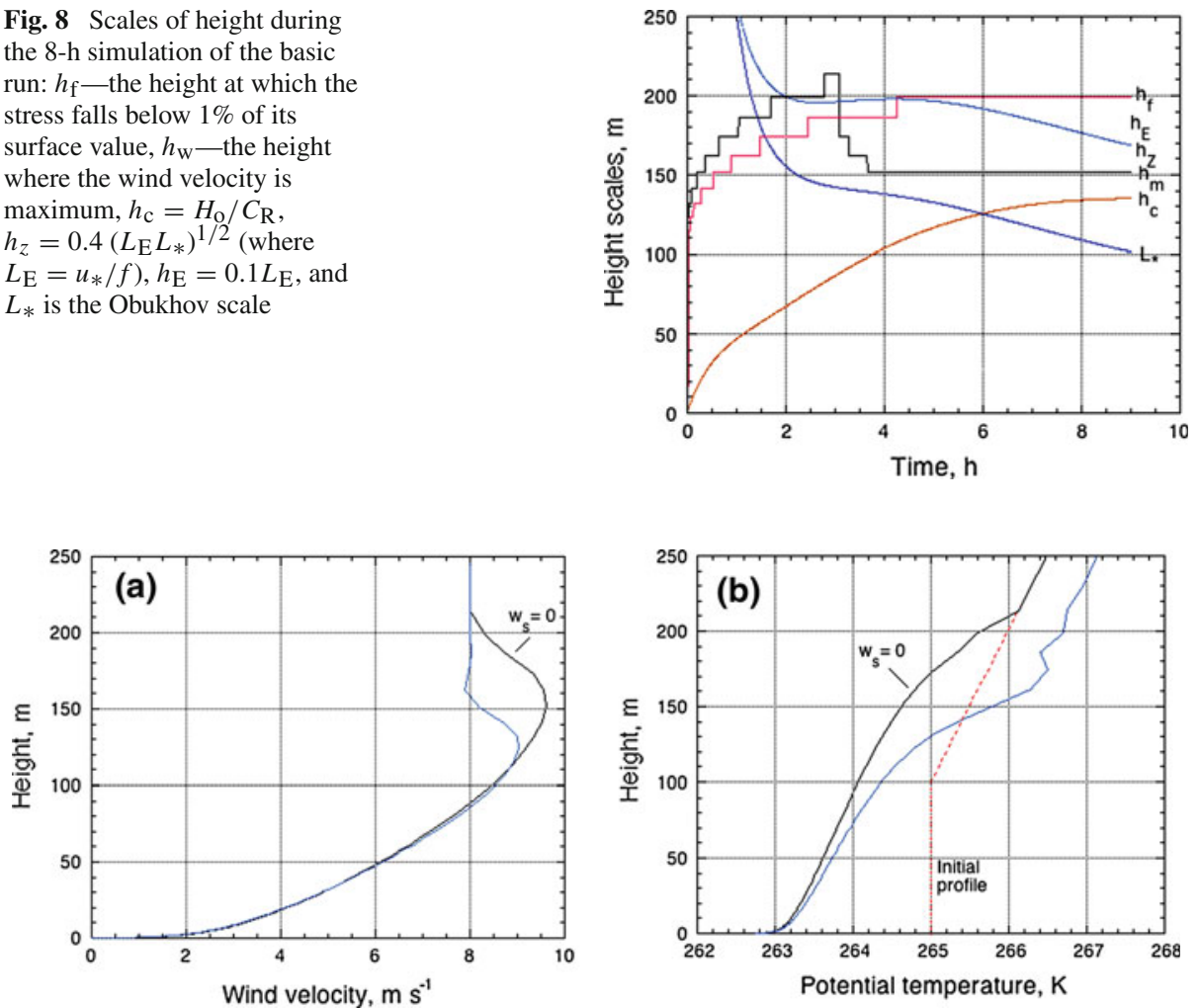

Fig. 9 Effects of subsidence velocity $w_{\mathrm{s}}$ : a wind-velocity modulus, b potential temperature. Black line the basic run, blue line the run with subsidence, the initial potential temperature profile is marked by a dashed line

\section{Effects of External Forcing}

\subsection{Subsidence}

In the SCM, subsidence is introduced through the component $-w_{\mathrm{s}} \partial \Theta / \partial z$, within the term $s_{\theta}$ on the right side of the temperature equations. Since $w_{\mathrm{s}}<0$, then $-w_{\mathrm{s}} \partial \Theta / \partial z>0$, and subsidence brings an additional source of heat into the boundary layer. The effects of subsidence are shown in Fig. 9. The wind and potential temperature profiles in simulations with subsidence are marked by blue lines, and in those without by black lines. Since subsidence gradually increases with height below the level of $z=50 \mathrm{~m}$, and is constant with height above this level, its effects are most pronounced in the upper part of the boundary layer and above it. Figure 9a shows the wind-velocity profile shifted downwards by subsidence, and as a result the depth of the boundary layer is smaller than in the case without subsidence. This conclusion is confirmed by the study of Mirocha and Kosovich (2010), based on large-eddy simulations. A similar effect can be noticed in Fig. 9b, which depicts the potential temperature profiles, where subsidence reduces the effect of cooling applied at the surface and diffused upward by turbulence. Above $z=150 \mathrm{~m}$, the warming effect (with respect to the initial profile) can be seen in the figure. It has to be noted that the considered case is not general, and depends on the adopted assumption on the distribution of the subsidence velocity with height. 

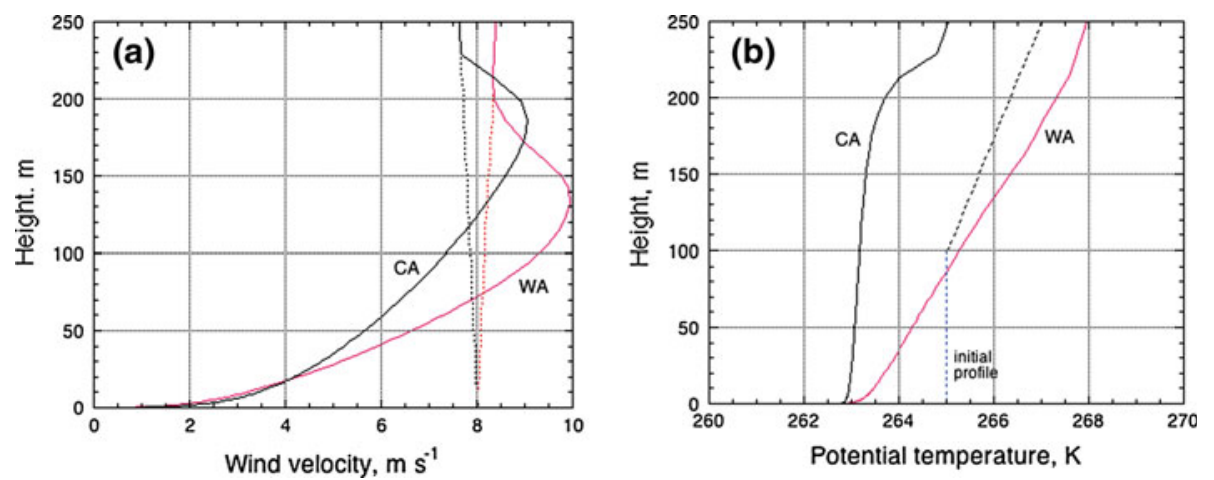

Fig. 10 Effects of baroclinicity: a wind-velocity modulus, b potential temperature (the initial profile is indicated by a blue dashed line). Profiles of the geostrophic wind modulus are indicated by dotted (black or red) lines. The cold-air advection profiles (CA) are marked by black lines, the red lines indicate the warm-air advection run (WA)

\subsection{Baroclinicity}

Baroclinicity is introduced in the SCM through additional terms in the momentum and temperature equations, with terms in the momentum equation modifying the geostrophic wind, and increasing or decreasing it with height. The baroclinic terms in the temperature equation introduce a positive or negative source of heat in the boundary layer.

Two baroclinic runs were performed, with $T_{x}=+1.5, T_{y}=-1.5 \mathrm{~m} \mathrm{~s}^{-1} \mathrm{~km}^{-1}$, and with $T_{x}=-1.5, T_{y}=+1.5 \mathrm{~m} \mathrm{~s}^{-1} \mathrm{~km}^{-1}$. In the first case, the baroclinic component, $-f\left(U T_{y}-\right.$ $\left.V T_{x}\right) / \beta$ (within the term $s_{\theta}$ on the right-hand side of the temperature equation) is positive, which implies warm-air advection. In the second case, the baroclinic term is negative, which implies cold-air advection. The effects of baroclinicity are depicted in Fig. 10; the black lines in the figure represent the cold-air advection run (CA), and the red lines denote the warm-air advection run (WA). Figure 10a shows the modulus of the wind velocity (solid lines) and the modulus of the geostrophic wind (dotted red and black lines). Changes of the geostrophic wind with height, within the $250 \mathrm{~m}$ layer, are relatively small, about $\pm 0.5 \mathrm{~m} \mathrm{~s}^{-1}$, but such minor changes cause significant differences in the magnitude and position of the low-level jet. The maximum wind speed of $10 \mathrm{~m} \mathrm{~s}^{-1}$ in run WA is located at the level of about $130 \mathrm{~m}$, and in run CA, the maximum wind speed of about $9 \mathrm{~m} \mathrm{~s}^{-1}$ is reached at about $185 \mathrm{~m}$.

As seen in Fig. 10b, the surface temperature in both runs, WA and CA, is the same (which is enforced by the boundary condition). Above the surface, the potential temperature is quite different in both runs due to baroclinicity. Note that the baroclinic component in the temperature equation, $-f\left(U T_{y}-V T_{x}\right) / \beta$ is zero at the surface and its modulus increases with height. Consequently, the upper part of the boundary is cooled during cold-air advection, and warmed during warm-air advection. This produces a potential temperature profile in Fig. 10b, more stable in the WA case and more neutral in the CA case. The surface temperature flux (not shown) in run WA, is smaller $\left(-0.0126 \mathrm{~K} \mathrm{~m} \mathrm{~s}^{-1}\right)$ than in run CA $\left(0.0048 \mathrm{~K} \mathrm{~m} \mathrm{~s}^{-1}\right)$, due to different potential temperature gradients near the underlying surface. The surface momentum flux is larger in cold-air advection $\left(0.062 \mathrm{~m}^{-2} \mathrm{~s}^{-2}\right)$ than during warm-air advection $\left(\approx 0.05 \mathrm{~m}^{-2} \mathrm{~s}^{-2}\right)$, and the depth of the boundary layer $h_{\mathrm{f}}$ is larger during cold-air advection than during warm-air advection. 


\section{Conclusions}

A numerical study of the stable boundary layer over a flat surface has been presented, based on a single-column model (SCM). The turbulence closure of the model follows the K-theory approach, with empirical stability functions of the Richardson number evaluated by using the SHEBA (Sorbjan 2010a,b; Sorbjan and Grachev 2010) and the CASES-99 data (Sorbjan 2011). A comparison of the SCM and results of two large-eddy simulations shows very good agreement of the considered profiles for wind velocity, temperature turbulent fluxes, and standard deviations of vertical velocity and temperature.

The reported experiments with the SCM have been designed to study the effects of surface cooling, the roughness length, the geostrophic wind, the Coriolis parameter, subsidence, and baroclinicity. The results show that, when cooling rates increase, the boundary-layer height decreases, the level of turbulence decreases, and the Richardson numbers increase. The smaller the roughness length $z_{0}$, the shallower is the boundary layer, and the smaller are the turbulent fluxes. As a result, the potential temperature in the boundary layer, obtained for a smooth underlying surface, is higher than would be the case for a rough surface. The development of the stable boundary layer depends on the inertial period $T_{i}=2 \pi / f$, and the smaller the Coriolis parameter $f$, the slower is the boundary-layer evolution.

The drag coefficient $u_{*} / G$ decreases when the Rossby number $R o=G /\left(f z_{\mathrm{o}}\right)$ increases, and increases when the stability parameter $\mu=\beta C_{\mathrm{R}} /\left(f^{2} G\right)$ decreases. The cross-isobar angle $\alpha$ decreases when $R o$ increases, and increases when $\mu$ increases. The heat transfer coefficient $T_{*} / T_{\mathrm{S}}$ (where $T_{\mathrm{S}}=C_{\mathrm{R}} / f$ ) decreases when $R o$ increases, and decreases when $\mu$ increases. The above rules apply for all time. The drag coefficient $u_{*} / G$ and the crossisobar angle $\alpha$ undergo inertial oscillations with a period $T_{i}$, while the ratio $T_{*} / T_{\mathrm{s}}$, however, monotonically increases with time, slowing, however, for large values of time. Subsidence introduces an additional source of heat into the boundary layer, where the effects are most pronounced in the upper part of the boundary layer. The depth of the boundary layer is reduced, and values of the surface fluxes are slightly reduced when subsidence is present.

Even small values of the thermal wind can cause significant changes in the magnitude and location of the low-level jet. The height of the maximum wind speed is smaller for warm-air advection than it is for cold-air advection. Since the modulus of the baroclinic term in the temperature equation increases with height, the resulting thermal stratification during coldair advection is closer to neutral, and more stable during warm-air advection. The depth of the boundary layer $h_{\mathrm{f}}$ is larger during cold-air advection than during warm-air advection.

The "upside-down" boundary layer cannot be attained within the presented SCM. The most intense turbulence always appears near the surface where shear is the largest. The inability of the SCM to simulate the "upside-down" boundary layer could be related to the fact that the model does not support the effects of breaking gravity waves, which generate turbulence in the upper portion of the stable boundary layer.

Acknowledgments This work has been supported by the US National Science Foundation grant ATM0938293.

Open Access This article is distributed under the terms of the Creative Commons Attribution Noncommercial License which permits any noncommercial use, distribution, and reproduction in any medium, provided the original author(s) and source are credited. 


\section{References}

André JC, Mahrt L (1982) The nocturnal surface inversion and influence of clear radiative cooling. J Atmos Sci 39:864-878

Andreas EL, Fairall CW, Guest PS, Persson POG (1999) An overview of the SHEBA Atmospheric Surface Flux Program. In: Proceedings of 13th symposium on boundary layers and turbulence. American Meteorological Society, Dallas, pp 550-555

Beare RJ, MacVean MK (2004) Resolution sensitivity and scaling of large-eddy simulations of stable boundary layer. Boundary-Layer Meteorol 112:257-281

Beare RJ, MacVean MK, Holtslag AAM, Cuxart J, Essau I, Golaz J-C, Jimenez MA, Kharoutdinov M, Kosovic B, Lewellen D, Lund TS, Lundguist JK, McCabe A, Moene AF, Noh Y, Raasch S, Sullivan $\mathrm{P}$ (2006) An intercomparison of large eddy-simulations of the stable boundary layer. Boundary-Layer Meteorol 118(2): 247-272. doi:10.1007/s10546-004-2820-6

Blackadar AK (1957) Boundary layer wind maxima and their significance for the growth of nocturnal inversions. Bull Am Meteorol Soc 38:283-290

Blackadar AK (1962) The vertical distribution of wind and turbulent exchange in neutral atmosphere. J Geophys Res 67:3095-3103

Blumen W, Banta RM, Burns SP, Fritts DC, Newsom R, Poulos GS, Sun J (2001) Turbulence statistics of a Kelvin-Helmholtz billow event observed in the night-time boundary layer during the Cooperative Atmosphere-Surface Exchange Study field program. Dyn Atmos Oceans 34:189-204

Brown AR, Derbyshire SH, Manson PJ (1994) Large-eddy simulation of stable atmospheric boundary layer with a revised stochastic subgrid model. Q J Roy Meteorol Soc 120:1485-1512

Businger JA (1973) Turbulent transfer in the atmospheric surface layer. In: Haugen DA (ed) Workshop on micrometeorology. American Meteorological Society, Boston, pp 67-100

Businger JA, Wyngaard JC, Izumi Y, Bradley EF (1971) Flux-profile relationships in the atmospheric surface layer. J Atmos Sci 28:181-189

Caughey SJ, Wyngaard JC, Kaimal JC (1979) Turbulence in the evolving stable boundary layer. J Atmos Sci 36(6):1041-1052

Chimonas H (1999) Steps, waves and turbulence in the stably stratified planetary boundary layer. BoundaryLayer Meteorol 90:397-421

Coulter RL, Doran JC (2002) Spatial and temporal occurrences of intermittent turbulence during CASES-99. Boundary-Layer Meteorol 105:329-349

Cuxart J, Yagüe C, Morales G, Terradellas E, Orbe J, Calvo J, Fernandez A, Soler MR, Infante C, Buenestado P, Espinalt A, Joergensen HE, Rees JM., Vila J, Redondo JM, Cantalapiedra IR, Conangla L (2000) Stable atmospheric boundary layer experiment in Spain (SABLES, 98). A report. Boundary-Layer Meteorol 96:337-370

Cuxart J, Holtslag AAM, Beare RJ, Bazile E, Beljaars A, Cheng A, Conangla AL, EK M, Fredman F, Hamdi R (2006) Single column model intercomparison for a stably stratified atmospheric boundary layer. Boundary-Layer Meteorol 118(2):273-303. doi:10.1007/s10546-005-3780-1

Delage Y (1974) A numerical study of the nocturnal atmospheric boundary layer. Q J Roy Meteorol Soc 100:351-364

Derbyshire SH, Wood N (1994) The sensitivity of stable boundary layers to small slopes and other influences. In: Stably Stratified flows: flow and dispersion over topography. Clarendon Press, Oxford, UK, 376 pp

Duynkerke PG (1991) Radiation fog: a comparison of model simulation with detailed observations. Mon Wea Rev 119(2):324-341

Duynkerke PG (1999) Turbulence, radiation and fog in Dutch stable boundary layers. Boundary-Layer Meteorol 90:447-477

Edwards JM, Beare RJ, Lapworth AJ (2006) Simulations of the observed evening transition and nocturnal boundary layers: single-column modelling. Q J Roy Meteorol Soc 132:61-80

Galmarini S, Beets C, Duynkerke PG, Vila-Guerau De Arellano J (1998) Stable nocturnal boundary layers: a comparison of one dimensional and large-eddy simulation models. Boundary-Layer Meteorol 88:181210

Garratt JR (1982) Observations in the nocturnal boundary layer. Boundary-Layer Meteorol 22:21-48

Ha K-J, Mahrt L (2003) Radiative and turbulent fluxes in the nocturnal boundary layer. Tellus 55:317-327

Kim J, Mahrt L (1992) Simple formulation of turbulent mixing in the stable free atmosphere and nocturnal boundary layer. Tellus 44A:381-394

Kosovic B, Curry JA (2000) A large-eddy simulations of a quasi-steady stratified atmospheric boundary layer. J Atmos Sci 57:1052-1068

Kustas W, Li F, Jackson J, Prueger J, MacPherson J, Wolde M (2004) Effects of remote sensing pixel resolution on modeled energy flux variability of croplands in Iowa. Remote Sens Environ 92:535-547 
Mahrt L (1999) Stratified atmospheric boundary layers. Boundary-Layer Meteorol 90:375-396

Mahrt L (2003) Contrasting vertical structures of nocturnal boundary layers. Boundary-Layer Meteorol 105:351-363

Mahrt L, Vickers D (2006) Extremely weak mixing in stable conditions. Boundary-Layer Meteorol 119:19-39

Mahrt L, Sun J, Blumen W, Delany T, Oncley S (1998) Nocturnal boundary-layer regimes. Boundary-Layer Meteorol 88:255-278

Mahrt L, Vickers D, Nakamura R, Soler MR, Sun J, Burns S, Lenschow DH (2001) Shallow drainage flows. Boundary-Layer Meteorol 101:243-260

Mirocha JD, Kosovich B (2010) A large-eddy simulation study of the influence of subsidence on the stably stratified atmospheric boundary layer. Boundary-Layer Meteorol 134:1-21

Monti P, Fernando HJS, Princevac M, Chan WC, Kowalewski TA, Pardyjak ER (2002) Observations of flow and turbulence in the nocturnal boundary layer over a slope. J Atmos Sci 59(17):2513-2534

Nappo CJ (1991) Sporadic breakdown of stability in the PBL over simple and complex terrain. BoundaryLayer Meteorol 54:9-87

Oncley SP, Foken T, Vogt R, Kohsiek W, de Bruin H, Bernhofer C, Christen A, van Gorsel E, Grantz D, Lehner I, Liebethal C, Liu H, Mauder M, Pitacco A, Ribeiro L, Weidinger T (2007) The energy balance experiment EBEX-2000. Part I: overview and energy balance. Boundary-Layer Meteorol 123:1-28

Poulos GS, Blumen W, Fritts DC, Lundquist JK, Sun J, Burns SP, Nappo C, Banta R, Newsom R, Cuxart J, Terradellas E, Balsley BB, Jensen ML (2002) CASES-99: a comprehensive investigation of the stable nocturnal boundary layer. Bull Am Meteorol Soc 83:555-581

Prandtl L (1932) Meteorologische Anwendungen der Stromungslehre. Beitr Phys Atmos 19:188-202

Raash S, Etling D (1991) Numerical simulations of rotating turbulent thermal convection. Beitr Phys Atmos 64:185-199

Raash S, Schröter M (2001) PALM — a large-eddy simulation model performing on massively parallel computers. Meteorol Z 10:363-372

Sarijarvi H (2009) Stable boundary layer: parameterizations for local and larger scales. Q J Roy Meteorol Soc 135:914-921

Schwarz P, Law B, Williams M, Irvine J, Kurpius M, Moore D (2004) Climatic versus biotic constraints on carbon and water fluxes in seasonally drought-affected ponderosa pine ecosystems. Glob Biochem Cycles 18:1029-1037

Sorbjan Z (2010a) Gradient-based scales and similarity laws in the stable boundary layer. Q J Roy Meteorol Soc 136:1243-1254

Sorbjan Z (2010b) Recent advances in the similarity theory of the stable boundary Layer. In: Zannetti P (ed) Chapter in Air quality modeling - theories, methodologies, computational techniques, and available databases and software, vol IV_-advances and updates. The EnviroComp Institute and the Air \& Waste Management Association, Fremont

Sorbjan Z (2011) The height correction of the gradient-based and flux-based similarity functions in the stable boundary layer. Boundary-Layer Meteorol. doi:10.1007/s10546-011-9653-x

Sorbjan Z, Balsley BB (2008) Microstructure of turbulence in the nocturnal boundary layer. Boundary-Layer Meteorol 129:191-210

Sorbjan Z, Grachev AA (2010) An evaluation of the flux-gradient relationship in the stable boundary layer. Boundary-Layer Meteorol 135(3):385-405

Sun J, Burns S, Delany AC, Oncley T, Horst A, Lenschow D (2003) Heat balance in nocturnal boundary layer during CASES-99. J Appl Meteorol 42:1649-1666

Sun J, Lenschow D, Burns S, Banta RM, Newsom RK, Coulter R, Frasier S, Ince T, Nappo C, Malsley BB, Jensen M, Mahrt L, Miller D, Skelly B (2004) Atmospheric disturbances that generate intermittent turbulence in nocturnal boundary layers. Boundary-Layer Meteorol 110:255-279

Sun X, Weng W, Taylor PA (2006) An evaluation of several turbulence closure schemes for modelling thermally induced slope flows. In: 17th AMS symposium on boundary layers and turbulence, San Diego, CA, USA

Tatarski VI (1961) Wave propagation in a turbulent medium. McGraw-Hill, New York, 285 pp

Thomas C, Martin JG, Goeckede M, Siqueira MBS, Foken T, Law BE, Loescher HW, Katul G (2008) Estimating daytime subcanopy respiration from conditional sampling methods applied to multi-scalar high frequency turbulence time series. Agric For 148:1210-1229

Van de Wiel BJH, Moene AF, Hartogenesis G, Bruin HA, Holtslag AAM (2003) Intermittent turbulence in the stable boundary layeor over land. Part III. A classification for observations during CASES-99. J Atmos Sci 60:2509-2522

Van de Wiel BJH, Moene AF, Steeneveld GJ, Baas P, Bosveld FC, Holtslag AAM (2010) A conceptual view on inertial oscillations and nocturnal low-level jets. J Atmos Sci 67:2679-2689. doi:10.1175/ 2010JAS3289.1 
Weng W, Taylor PA (2006) Modelling the one-dimensional stable boundary layer with an E $-\ell$ turbulence closure scheme. Boundary-Layer Meteorol 118:305-323

Zilitinkevich SS (1972) On the determination of the height of the boundary Ekman layer. Boundary-Layer Meteorol 3:131-145 